\title{
"Superior Rectus Paralysis" due to Inferior Rectus Myxedema
}

\author{
Hidenori Hattori, Eiichiro Nagata, Hiroaki Kimura and Norihiro Suzuki \\ Key words : dysthyroid orbitopathy, enhanced CT, euthyroid opthalmopathy, subclinical hypothyroidism, \\ myxedema
}

(DOI : 10.2169/internalmedicine.45.6187)

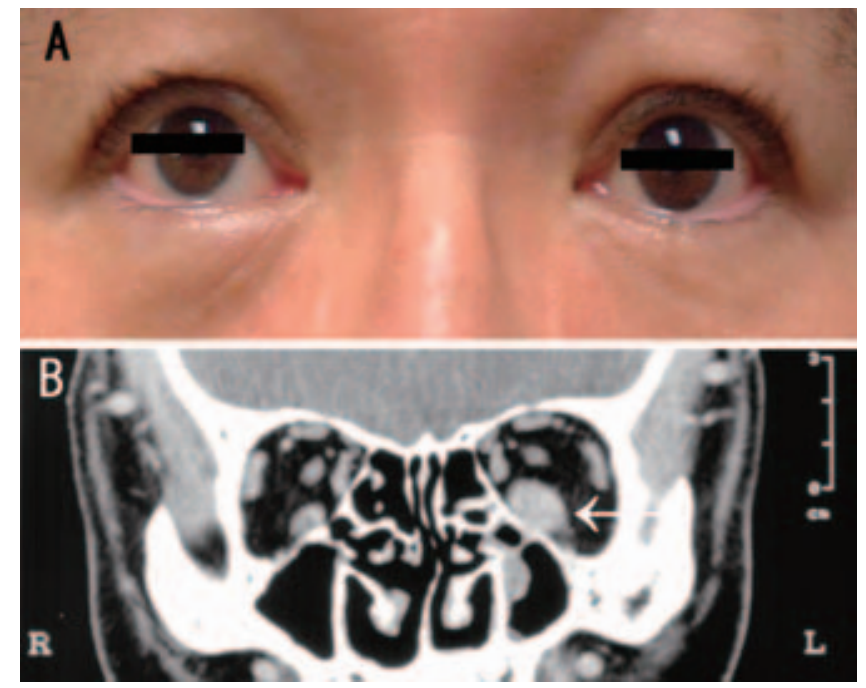

Figure 1.

\section{Short summary}

A 56-year-old man presenting with double vision as a subjective symptom was admitted to our hospital. He had been diagnosed as having left superior rectus paralysis by an ophthalmologist at another university hospital, because of loss of upward gaze of the left eye (Fig. 1 A). At that hospital, head MRI/MRA, ophthalmologic examination, and serologic examination were performed, but did not reveal remarkable findings. In our hospital, subclinical hypothyroidism (fT $32.5 \mathrm{pg} / \mathrm{ml}$, fT $41.0 \mathrm{ng} / \mathrm{dl}$, TSH $10.7 \mathrm{mIU} / \mathrm{l}$, TPO Antibody negative) and glucose intolerance were detected, but a malignancy survey including Ga-scintigraphy was negative. Enhanced orbital cavity CT revealed thickening of the left inferior rectus muscle indicating myxedema and inflammation (Fig. $1 \mathrm{~B}$, arrow), and we diagnosed dysthyroid orbitopathy (1). Levothyroxine and prednisolone were prescribed, and his double vision gradually improved. Finally his serologic examination was improved (fT $33.3 \mathrm{pg} / \mathrm{ml}$, fT $41.2 \mathrm{ng} / \mathrm{dl}$, TSH $4.61 \mathrm{mIU} / \mathrm{l}$ ). This case indicated that myxedema could restrict muscle extension.

Department of Neurology, School of Medicine, Keio University, Tokyo

Received for publication August 18, 2006 ; Accepted for publication September 4, 2006

Correspondence to Dr. Hidenori Hattori, Department of Neurology, School of Medicine, Keio University, 35 Shinanomachi, Shinjuku-ku, Tokyo $160-8582$ 
DOI : 10.2169/internalmedicine.45.6187

\section{References}

1. Jacobson DM. Dysthyroid orbitopathy. Semin Neurol 20 : 43-54, 2000.

(C) 2006 The Japanese Society of Internal Medicine http://www.naika.or.jp/imindex.html 